\title{
Journal of Agricultural and Food Chemistry
}

Msc: jf6b01296

The following graphic will be used for the TOC:

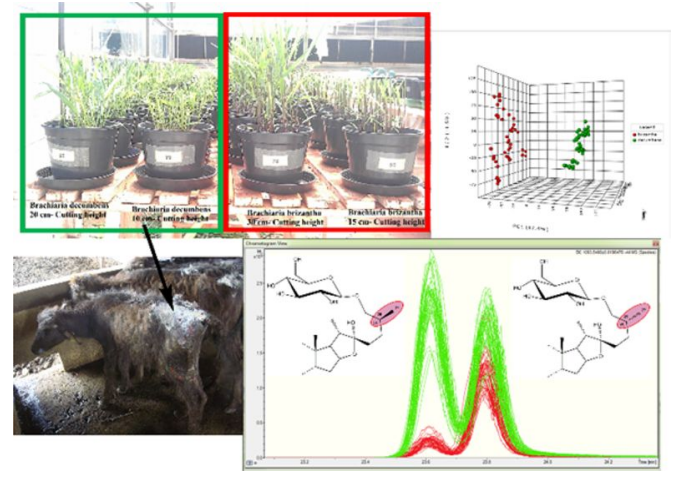




\title{
Ultrahigh-Performance Liquid Chromatography-High-Resolution Quadrupole Time-of-Flight Mass Spectrometry Based Metabolomics Reveals Key Differences between Brachiaria decumbens and B. brizantha, Two Similar Pastures with Different Toxicities
}

\author{
${ }_{5}$ Andy J. Pérez, ${ }^{*}{ }^{\dagger}$ Syeda M. Hussain, ${ }^{\ddagger}$ Eukasz Pecio, ${ }^{\dagger}$ Mariusz Kowalczyk, ${ }^{\dagger}$ Valdo Rodrigues, ${ }^{\dagger}$
} 6 and Anna Stochmal ${ }^{\dagger}$

$7{ }^{\dagger}$ Department of Biochemistry and Crop Quality, Institute of Soil Science and Plant C

8 ul. Czartoryskich 8, 24-100, Puławy, Poland Valdo R. Herling

$9{ }^{\star}$ Department of Plant Sciences, College of Animal Sciences and Food Engineering, University of São Paulo, Pirassununga,

10 São Paulo 13635-900, Brazil

ABSTRACT: Several species of Brachiaria (Poaceae) currently cover extensive grazing areas in Brazil, providing valuable source of feed for a large cattle population. However, numerous cases of toxicity outbreaks in livestock have raised concerns on safety of using these plants, especially $B$. decumbens. In this study, chemometric analysis of ultrahigh-performance liquid chromatographyhigh-resolution quadrupole time-of-flight mass spectrometry (UHPLC-HR-QTOF-MS) data has for the first time uncovered qualitative and quantitative differences between metabolomes of toxic B. decumbens and nontoxic B. brizantha. The steroidal saponin protoneodioscin was established as the main biomarker for B. decumbens when compared to B. brizantha, and therefore the key explanation for their phytochemical differentiation. Quantification of protodioscin in both plants showed no significant differences; consequently, the idea that this compound is solely responsible for toxicity outbreaks must be discarded. Instead, we propose that the added occurrence of its stereoisomer, protoneodioscin, in B. decumbens, can be considered as the probable cause of these events. Interestingly, the greatest concentrations of saponins for both species were reached during winter (B. decumbens $=53.6 \pm 5.1 \mathrm{mg} \cdot \mathrm{g}^{-1}$ dry weight (D.W.); B. brizantha $=25.0 \pm 1.9 \mathrm{mg} \cdot \mathrm{g}^{-1}$ D.W. $)$ and spring $($ B. decumbens $=$ $49.4 \pm 5.0 \mathrm{mg} \cdot \mathrm{g}^{-1}$ D.W.; B. brizantha $=27.9 \pm 1.4 \mathrm{mg} \cdot \mathrm{g}^{-1}$ D.W.), although in the case of $B$. decumbens these values do not vary significantly among seasons.

KEYWORDS: Brachiaria decumbens, Brachiaria brizantha, UHPLC-MS metabolomics, multivariate data analysis, saponin quantification

\section{INTRODUCTION}

28 With the world's biggest cattle population of over 200 million 29 head, Brazil is currently one of the largest beef producing 30 countries in the world. ${ }^{1}$ This production is largely dependent 31 on pasture areas due to easy availability and low costs. The $3285 \%$ of Brazil's pasture areas is covered by various species of 33 Brachiaria, $^{2}$ of which $B$. decumbens and B. brizantha are the two 34 most prominent species.

35 Along with holding large cattle population, Brazil is also 36 facing poisoning cases by plants, ${ }^{3,4}$ described in literature as 37 one of the three main reasons causing farm animal's death. ${ }^{5}$ 38 Brachiaria spp., especially $B$. decumbens, are on the top of the 39 list of such plants, ${ }^{4}$ which have been reported as the cause of 40 hepatotoxic photosensitization outbreaks among goats, sheep, 41 and cattle. ${ }^{3,6}$ Initially, Brachiaria spp. toxicity was associated 42 with sporidesmin mycotoxin produced by Pithomyces chartarum 43 fungus; but later investigations suggested that steroidal 44 saponins, mainly protodioscin, contained in this plant are the 45 root of the problem by induction of crystal formation in the 46 biliary system. $^{7-10}$ A mechanism has been proposed in which 47 saponins are hydrolyzed in the digestive tract, producing 48 epi-smilagenin and epi-sarsapogenin. Detoxification of these compounds by conjugation with glucuronic acid yields 49 glucuronides that bind calcium ions to form insoluble salt de- 50 posited in the form of crystals. ${ }^{3}$ This causes photosensitization 51 in an indirect manner, by damaging either hepatocytes and/or 52 bile ducts, thus disrupting the liver's ability to excrete phyto- 53 porphyrin (phylloerythrin: a chlorophyll post digestion meta- 54 bolite) into the gastrointestinal tract via the biliary system. ${ }^{11} 55$ Then, photosensitization occurs due to accumulation of phyto- 56 porphyrin in livestock liver and skin, which upon exposure to 57 sunlight results in excitation of this photoactive molecule, 58 causing liver injury, jaundice, skin problems, anorexia, nervous- 59 ness, and death in some cases. ${ }^{3,11}$

The majority of the poisoning outbreaks reported in Brazil 61 have been caused by $B$. decumbens, while intoxications involving 62 other species, such as B. brizantha, are less frequent. ${ }^{3}$ For 63 this reason, the replacement of $B$. decumbens by the less toxic 64 $B$. brizantha has been implemented through the last 20 years, 65

Received: March 19, 2016

Revised: April 26, 2016

Accepted: May 18, 2016 


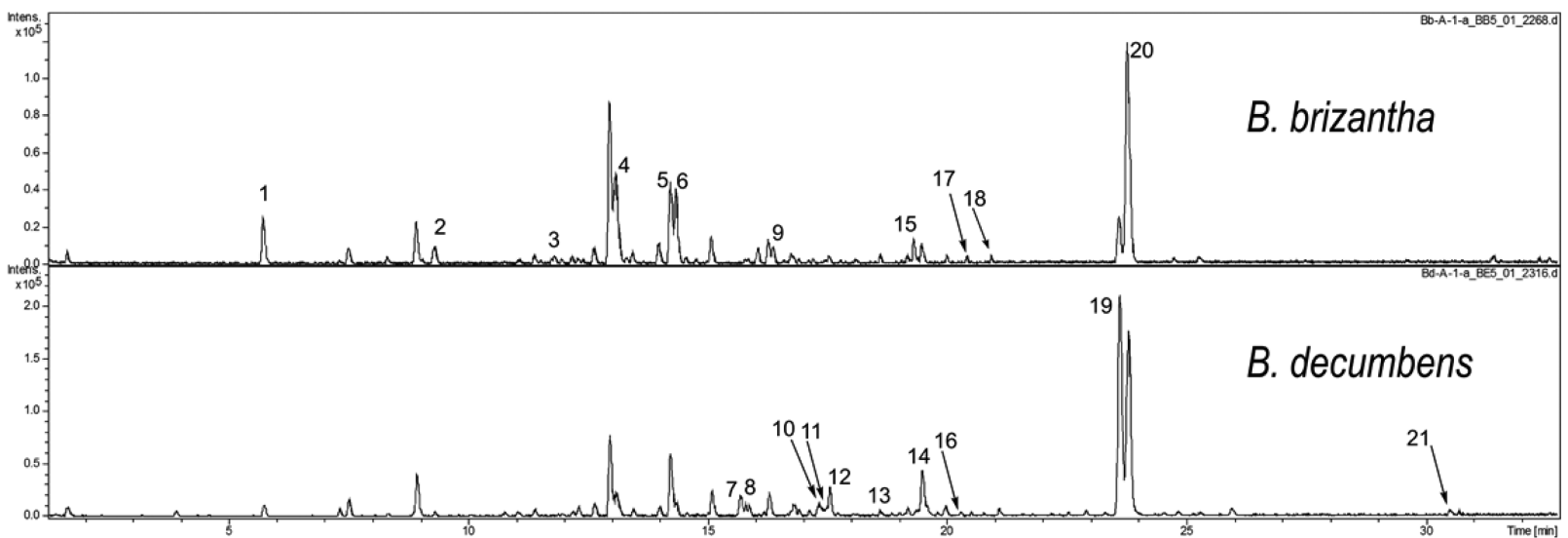

Figure 1. Base peak chromatograms in negative ion mode on a C-18 column for B. decumbens and B. brizantha extracts showing the most important metabolites for their differentiation.

66 resulting in a decrease of outbreaks. ${ }^{3}$ The concentration of 67 protodioscin in these two species in different stages of growth 68 has been measured by many authors; however, the results are 69 contradictory, showing not significant differences and even very 70 low or undetectable levels in some cases of outbreak. ${ }^{3,12}$ This 71 calls into question not only the attribution of Brachiaria spp. 72 toxicity to protodioscin, but also the reliability of measuring 73 methods previously employed. The determination of varia74 tion between the metabolome (all metabolites, i.e., small-size 75 molecules, intermediates, or end products of metabolic 76 processes present in biological system) ${ }^{13}$ of $B$. decumbens and $77 \mathrm{~B}$. brizantha samples is therefore needed as an overview that 78 could help to identify components potentially responsible for 79 the toxicity.

80 Metabolomics technology has emerged as a suitable research 81 strategy for the profiling of endogenous plant metabolites, ${ }^{14}$ 82 and it has been successfully applied in the determination 83 of metabolites who contribute most to the distinction between 84 the metabolome of genetically closed species. ${ }^{15,16}$ In the present 85 study, we applied a nontargeted reversed-phase ultrahigh86 performance liquid chromatography-high-resolution quadrupole 87 time-of-flight mass spectrometry (UHPLC-HR-QTOF-MS) 88 metabolomics approach to investigate the variation in the meta89 bolite profiles between $B$. decumbens and B. brizantha samples 90 harvested during different seasons and stages of growth. 91 Multivariate analysis techniques, including principal component 92 analysis (PCA) and partial least square discriminant analysis 93 (PLS-DA), were applied to the data mining. Tandem mass 94 spectrometry (MS/MS), metabolite database of METLIN 95 (https://metlin.scripps.edu/), ${ }^{17}$ authentic standard compounds, 96 and the literature were used for the identification of phyto97 chemicals which most contribute to the separation of these 98 two species. In addition, the main identified biomarker for 99 distinguishing groups was isolated, characterized, and quantified 100 in all samples.

\section{MATERIALS AND METHODS}

102 Chemicals. Acetonitrile hypergrade for LC-MS and methanol 103 HPLC grade were purchased from Merck (Darmstadt, Germany). 104 Water was purified in-house with a Milli- $Q$ water purification system 105 (Millipore Co.). Formic acid MS-grade, eluent additive for LC-MS, 106 was obtained from Sigma-Aldrich.

107 Plant Material. Authenticated seeds of B. decumbens stapf 108 (cv. Basilisk) and B. brizantha (Hochst. ex A. Rich stapf; cv. Xaraés) 109 were provided by Matsuda (Rebeirao Preto, Brazil) and planted in a 110 greenhouse at the College of Animal Science and Food Engineering
(Pirassununga-USP, Brazil), located at $21^{\circ} 59^{\prime} \mathrm{N}, 47^{\circ} 25^{\prime} \mathrm{W}$ and 111 $635 \mathrm{~m}$ altitude. The climate is classified as CWA with average annual 112 precipitation of $1.238 \mathrm{~m}$ and relative humidity of $73 \%$. The daylight 113 length and sunshine hour averages were of 12.8 and $160.5 \mathrm{~h}$ for 114 summer (January), 11.2 and $174.5 \mathrm{~h}$ for autumn (April), 11.0 and 115 $177.0 \mathrm{~h}$ for winter (July), and 12.6 and $158.3 \mathrm{~h}$ for spring (October), 116 respectively. The recorded highest and lowest temperatures were of 117 39.2 and $20.5{ }^{\circ} \mathrm{C}$ for summer, 31.3 and $13.6{ }^{\circ} \mathrm{C}$ for autumn, 27.8 and 118 $9.9^{\circ} \mathrm{C}$ for winter, and 33.0 and $14.3^{\circ} \mathrm{C}$ for spring, respectively. Plant 119 aerial parts were harvested in triplicate at two different heights 120 (B. decumbens, 10 and $20 \mathrm{~cm}$, and B. brizantha, 15 and $30 \mathrm{~cm}$ ) in 121 spring, summer, autumn, and winter, exactly before sunrise, under 122 CRBD and were morphologically separated. Plant materials were cut 123 down into pieces of $\leq 3 \mathrm{in}$. length, and after drying under $40{ }^{\circ} \mathrm{C}$ were 124 ground on a Wiley Mini Mill at 16 mesh size and stored in black 125 plastic bottles for further uses.

126

Sample Preparation. Each sample was independently processed 127 (24 total herb samples per species). Extraction was performed on a 128 Dionex ASE 200 extractor (Dionex Corp., Sunnyvale, CA, U.S.A.). 129 Portions of $150 \mathrm{mg}$ of the dried and ground herb samples were mixed 130 with diatomaceous earth (Dionex ASE Prep DE, Dionex Corp., 131 Sunnyvale, CA, U.S.A.) and placed in $5 \mathrm{~mL}$ stainless steel extraction 132 cells. A cellulose filter (Dionex Corp.) together with $1 \mathrm{~g}$ of LiChroprep 133 $\mathrm{RP}-18(40-63 \mu \mathrm{m})$ (Merck, Darmstadt, Germany) were placed at the 134 bottom of the extraction cells to facilitate chlorophyll removal. 135

The cells were filled with extraction solvent (80\% methanol in 136 water, v/v), pressurized at $1500 \mathrm{psi}$, and heated at $60{ }^{\circ} \mathrm{C}$ for $5 \mathrm{~min}$ to 137 ensure that samples reached thermal equilibrium. Samples were then 138 extracted by three static cycles of $5 \mathrm{~min}$ each at the experimental 139 temperature and pressure. After extraction, cells were rinsed with fresh 140 solvent ( $60 \%$ of the cell volume) and purged with a flow of nitrogen 141 for $100 \mathrm{~s}$. The extracts $(25 \mathrm{~mL}$ each $)$ were collected into the $60 \mathrm{~mL} 142$ glass vials, evaporated to dryness using rotary evaporator at $40{ }^{\circ} \mathrm{C}, 143$ suspended in $1 \mathrm{~mL}$ of $20 \%$ methanol, and stored at $-20{ }^{\circ} \mathrm{C}$ until 144 required.

Before LC-MS analysis, each extract was sonicated for $10 \mathrm{~min}, 146$ followed by centrifugation at $13000 \mathrm{rpm}$ for $20 \mathrm{~min}$ and $22^{\circ} \mathrm{C}$ using a 147 Sigma 3-16KL refrigerated centrifuge (Sigma Laborzentrifugen $\mathrm{GmbH}, 148$ Osterode am Harz, Germany). Aliquots of the supernatants (5 $\mu \mathrm{L} 149$ each) were taken and brought to $1 \mathrm{~mL}$ with $20 \%$ acetonitrile in water 150 (v/v) and subsequently analyzed by UHPLC-HR-QTOF-MS with 151 two technical replications ( 96 total runs).

UHPLC-HR-QTOF-MS Analyses. UHPLC analysis was per- 153 formed on a Dionex UltiMate 3000RS ultrahigh-performance liquid 154 chromatographic system with a charged aerosol detector (Thermo 155 Scientific, Dionex, Germany), interfaced with a high-resolution quadru- 156 pole time-of-flight mass spectrometer (HR/Q-TOF/MS, Impact II, 157 Bruker Daltonik GmbH, Bremen, Germany). Chromatographic separa- 158 tion of Brachiaria metabolome was performed on an Acquity UPLC 159 BEH C18 column $(100 \mathrm{~mm} \times 2.1 \mathrm{~mm}, 1.7 \mu \mathrm{m}$, Waters, Manchester, 160 
161 U.K.) maintained at $30{ }^{\circ} \mathrm{C}$. The mobile phase consisted of solvent A $162(0.1 \%$ formic acid in Milli-Q water, v/v) and solvent B ( $0.1 \%$ formic 163 acid in acetonitrile, $\mathrm{v} / \mathrm{v}$ ) at a flow rate of $0.4 \mathrm{~mL} \cdot \mathrm{min}^{-1}$. The gradient 164 elution was as follows: $2 \% \mathrm{~B}$ from 0 to $1 \mathrm{~min}$, then concavely increased 165 to $20 \%$ B in $20 \mathrm{~min}$, followed by concave increase to $28 \%$ B in 8 min 166 and another increase to 55\% B in 5 min. The column was eluted with 167 this concentration of solvent B for 2 min more and then was re168 equilibrated with $2 \%$ B for $5 \mathrm{~min}$. Samples were kept at $15{ }^{\circ} \mathrm{C}$ in the 169 autosampler. The injection volume was $5.0 \mu \mathrm{L}$. The mass spectrometer 170 was operated in the negative electrospray ionization mode after 171 confirmation of low sensitivity and poor resolution in the positive 172 mode. The following parameters were used: capillary voltage was set at $1732.8 \mathrm{kV}$; nebulizer $0.7 \mathrm{bar}$; dry gas $6.0 \mathrm{~L} \cdot \mathrm{min}^{-1}$; dry temperature $200^{\circ} \mathrm{C}$. 174 The mass scan range was set as $150-2000 \mathrm{~m} / z$. MS/MS spectra were 175 acquired in a data-dependent manner, whereby ions (maximum 2) from 176 each scan were subjected to collision-induced fragmentation if their 177 absolute intensity exceeded 1800 counts. Depending on ion's $\mathrm{m} / z$, 178 variable collision energy in range from 15 to $35 \mathrm{eV}$ was used. Internal 179 calibration was achieved with $10 \mathrm{mM}$ sodium formate solution 180 introduced to the ion source via a $20 \mu \mathrm{L}$ loop at the beginning/end 181 of each analysis using a six-port valve. Calibration was carried out using 182 high-precision calibration mode (HPC). Data were collected and 183 processed by the software DataAnalysis 4.3 (Bruker Daltonik GmbH, 184 Germany).

185 Data Processing and Analysis. ProfileAnalysis software (version 186 2.1, Bruker Daltonik GmbH, Germany) was used to preprocess the 187 raw UHPLC-QTOF-MS data. ProfileAnalysis parameters were set 188 as follows: advanced bucket generation with retention time range of $1891.0-32.0 \mathrm{~min}$, mass range of $150-1200 \mathrm{~m} / z$, normalization to sum of 190 peaks, background subtraction, and time alignment. LC-MS analyses 191 were processed with the Find Molecular Futures (FMF) function to 192 create compounds (molecular features) with signal-to-noise threshold 193 of 3 for peak detection. Generated bucket table consisting of $\mathrm{m} / \mathrm{z}-$ 194 retention time pairs and respective compound intensity was exported 195 and uploaded to MetaboAnalyst, ${ }^{18}$ which is an open bioinformatics 196 Web site providing an analytical pipeline for high-throughput meta197 bolomics studies. The univariate analysis volcano plot, a common 198 method used for exploratory data analysis, was performed. This provides 199 a preliminary overview of features that are potentially significant for 200 separation of the two groups. The multivariate PCA and PLS-DA were 201 performed after rowwise normalization based on sum of peak areas and 202 Pareto scaling, to investigate the overall variation in the metabolome of 203 Brachiaria species. In addition, intraspecies variations for both species 204 were also investigated using separate PCA models and dendrograms for 205 each species.

206 Isolation and Structural Characterization of Saponin Stand207 ards. Extracts of both plants, obtained as described above, were 208 loaded onto a $12 \mathrm{~cm} \times 1.5 \mathrm{~cm}$ column packed with Sephadex LH-20 209 (Sigma-Aldrich, Steinheim, Germany) and eluted with isocratic 210 methanol/water $(8: 2, \mathrm{v} / \mathrm{v})$ mobile phase. Two milliliter fractions 211 were collected and checked by TLC on silica gel RP- $18 \mathrm{~F}_{254} \mathrm{~S}$ plates 212 (Merck, Darmstadt, Germany), developed with acetonitrile/water/ 213 formic acid $(4: 6: 0.5, \mathrm{v} / \mathrm{v})$, sprayed with Liebermann-Burchard reagent, 214 and heated at $130{ }^{\circ} \mathrm{C}$. A major fraction was obtained, which yielded the 215 pure compounds 19 (protoneodioscin) (19 $^{19}$ and 20 (protodioscin) $)^{19,20}$ 216 after a purification procedure on a semipreparative HPLC chromato217 graphic system equipped with a Gilson 321 pump, a Gilson GX-271 218 liquid handler, a Gilson Prep ELS II detector, and a semipreparative 219 reversed-phase column Atlantis Prep T3 $(250 \mathrm{~mm} \times 10 \mathrm{~mm}$ i.d., $5 \mu \mathrm{m}$, 220 Waters, Milford, MA). The separation was carried out isocratically at $22130{ }^{\circ} \mathrm{C}$ using $3 \mathrm{~mL} \cdot \mathrm{min}^{-1}$ flow of $25 \%$ acetonitrile (cont. $0.2 \%$ formic 222 acid). The purity and structures of isolated compounds were confirmed 223 by mass spectrometry and NMR spectroscopy. 1D and 2D NMR 224 spectra $\left({ }^{1} \mathrm{H},{ }^{13} \mathrm{C}\right.$, HSQC, HMBC, ${ }^{1} \mathrm{H}-{ }^{1} \mathrm{H}$ COSY DQF, TROESY $)$ 225 were recorded on a Bruker Avance III HD Ascend-500 spectrometer 226 equipped with $5 \mathrm{~mm}{ }^{1} \mathrm{H}\left\{{ }^{109} \mathrm{Ag}-{ }^{31} \mathrm{P}\right\}$ broad-band inverse (BBI) probe, 227 in pyridine- $d_{5} /$ deuterated water $\left(95: 5, \mathrm{v} / \mathrm{v}\right.$ ) at $30{ }^{\circ} \mathrm{C}$ (see Supporting 228 Information Figures S9-S18). Exact mass and MS/MS fragmentation 229 patterns were determined on an HR/Q-TOF/MS (Impact II, Bruker
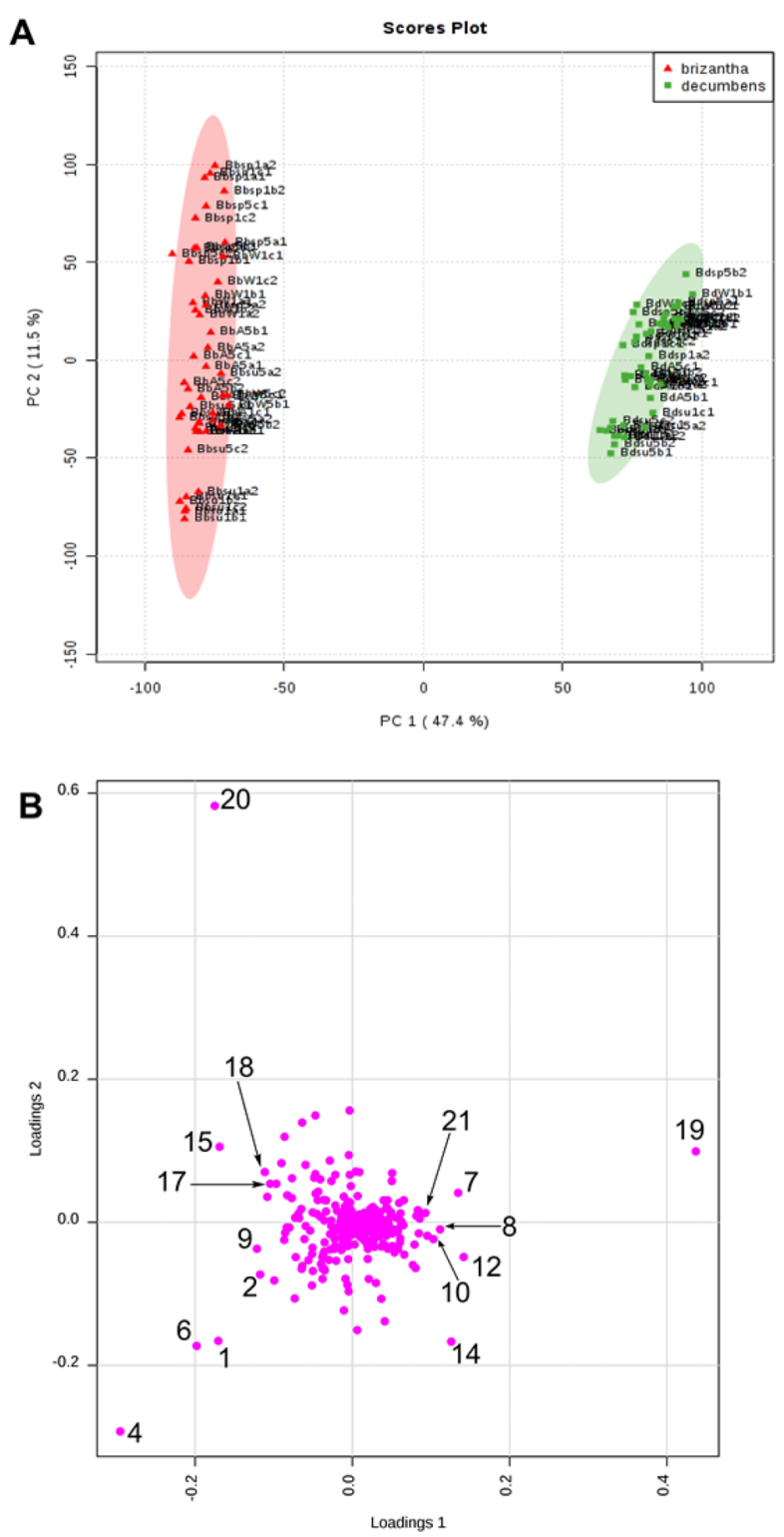

Figure 2. (A) PCA scores plot based on UHPLC-MS data showing separation of B. brizantha (red filled triangles) and B. decumbens (green filled squares), together with their respective $95 \%$ confidence regions. The explained variances are shown in brackets. (B) The corresponding loadings scatter plot showing the compounds that are correlated to separation in scores plot.

Daltonik GmbH, Bremen, Germany) (see Supporting Information 230 Figures S19 and S20).

Calibration Curves of Standard Compounds. The pure saponins 232 prepared as described above were taken to prepare $0.1 \mathrm{mg} \cdot \mathrm{mL}^{-1} 233$ stock solutions in $50 \%$ acetonitrile, which were subsequently stored 234 at $-20{ }^{\circ} \mathrm{C}$. Standard working solutions used for calibration were 235 prepared by diluting the stock solutions with $20 \%$ acetonitrile to the 236 desired concentrations. Each calibration curve was constructed by 237 running standard at five different concentrations in triplicate. 238

UPLC Quantitative Analysis. Brachiaria samples were analyzed 239 using a Waters ACQUITY UPLC system coupled to a Waters TQ 240 detector (Waters Corp.) in selected ion monitoring (SIM) mode and 241 operated in positive electrospray ion mode, set to $m / z 1071.5[\mathrm{M}+\mathrm{Na}]^{+} 242$ for both compound 19 and 20. The following instrumental parameters 243 were used for ESI-MS analysis: capillary voltage, $3.1 \mathrm{kV}$; cone voltage, 244 $110 \mathrm{~V}$; desolvation gas, $\mathrm{N}_{2} 800 \mathrm{~L} / \mathrm{h}$; cone gas, $\mathrm{N}_{2} 100 \mathrm{~L} / \mathrm{h}$; source temp, 245 $140{ }^{\circ} \mathrm{C}$; desolvation temp, $350{ }^{\circ} \mathrm{C}$; dwell time, $300 \mathrm{~ms}$. Waters MassLynx 246 software v.4.1 was used for acquisition and data processing. 247 
A
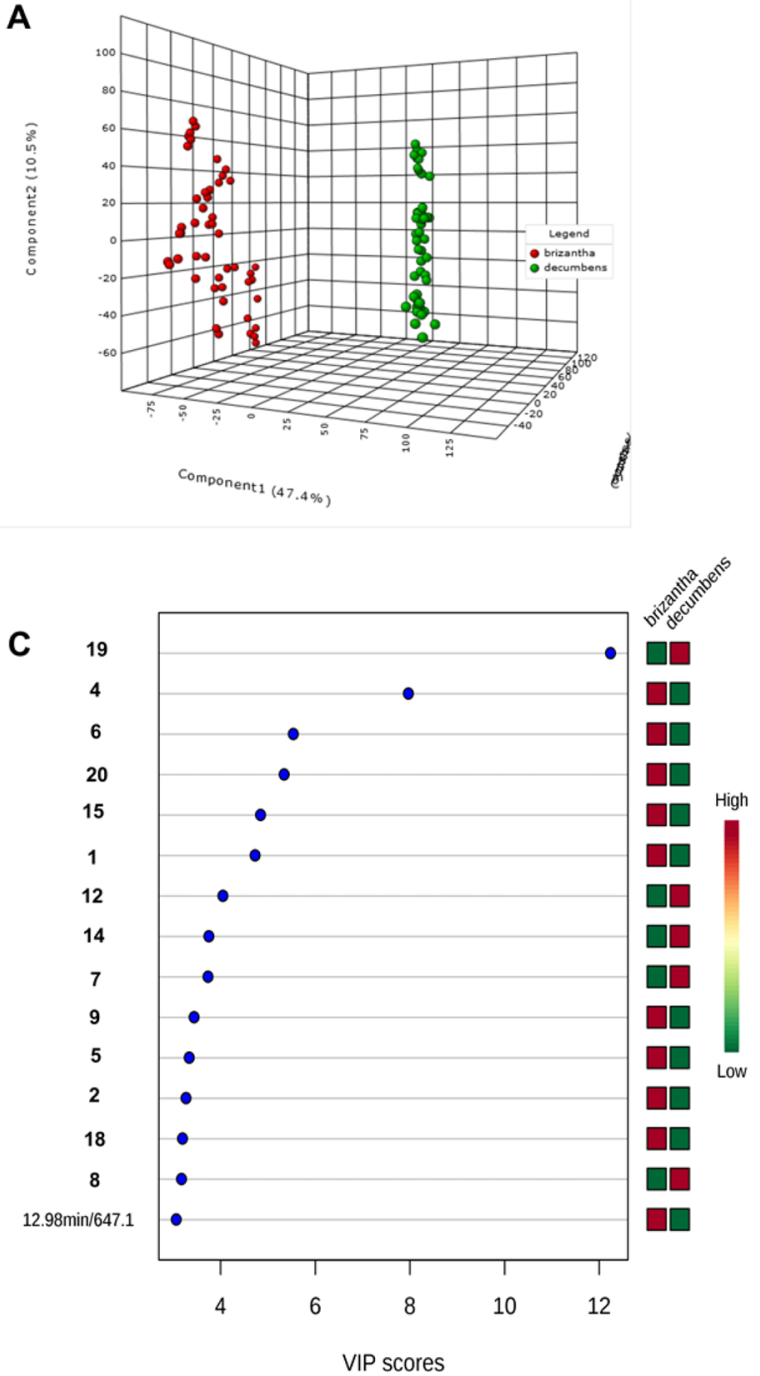

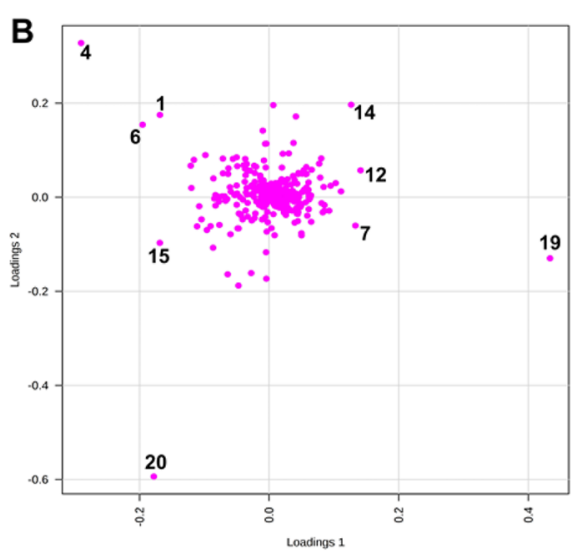

D

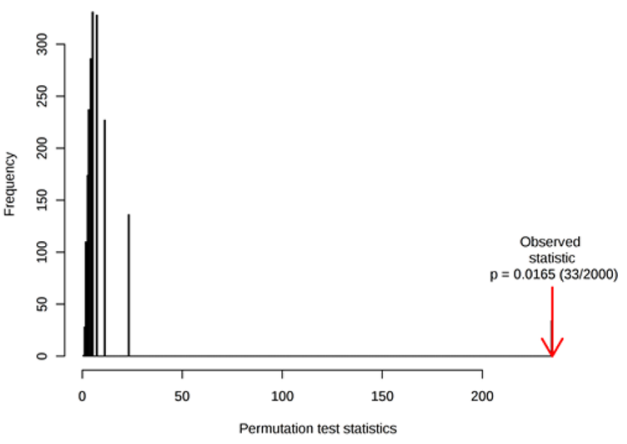

Figure 3. PLS-DA of metabolites between B. brizantha and B. decumbens. (A) Three-dimensional scores plot using the three first components, accounting for $47.4 \%, 10.5 \%$, and $4.1 \%$ of the total variance. (B) Loadings plot showing variables responsible for discrimination in scores plot. (C) Variables important in projection (VIP) scores of 15 top contributors to PLS-DA component 1. (D) PLS-DA model validation by permutation tests based on separation distance $(B / W$ ratio), with a $p$-value based on permutation as $p=0.0165(33 / 2000)$.

248 Samples were separated on a BEH C18 column $(100 \mathrm{~mm} \times$ $2492.1 \mathrm{~mm}, 1.7 \mu \mathrm{m}$, Waters, Manchester, U.K.), which was maintained 250 at $25{ }^{\circ} \mathrm{C}$. The flow rate was adjusted to $0.4 \mathrm{~mL} \cdot \mathrm{min}^{-1}$. The mobile 251 phase consisted of isocratic $21 \%$ acetonitrile in Milli-Q water (v/v) 252 with $0.1 \%$ formic acid. Samples were kept at $8{ }^{\circ} \mathrm{C}$ in the autosampler. 253 The injection volume was of $2.0 \mu \mathrm{L}$ (partial loop with needle overfill 254 mode). The separation was completed in $35 \mathrm{~min}$.

255 Statistical analyses of the data were performed using GraphPad 256 Prism 5.0. The variables were tested for normality and fitted to a 257 Gaussian distribution. Two-way analysis of variance (ANOVA) analyses 258 were performed to test how the concentrations of saponins were 259 affected by species and seasons, as well as one-way ANOVA to 260 investigate the variation within cutting-heights. Statistical significance 261 was declared at $p<0.05$

\section{$262 \square$ RESULTS AND DISCUSSION}

263 As part of an agricultural trial developed in Brazil, aerial parts of $264 \mathrm{~B}$. decumbens and B. brizantha were harvested in triplicate at 265 two different heights in spring, summer, autumn, and winter. 266 After drying, herb samples were finely ground and subjected 267 to automated extraction with $80 \%$ methanol. The separation 268 of Brachiaria extracts was carried out on a UHPLC system interfaced with an HR/Q-TOF/MS within $40 \mathrm{~min}$. Visual 269 examination of their typical base peak ion chromatograms 270 obtained in negative ESI mode displayed clear differences 271 (Figure 1), which resulted in the detection of 813 features 272 (metabolite ions) after peak alignment.

Differentiation of Brachiaria Metabolome. In order to 274 explore the phytochemical variation in the UHPLC-MS data, 275 the generated chromatograms were used for a chemometric 276 analysis since they provide a comprehensive chemistry overview 277 of the two species. Volcano plot (Supporting Information, 278 Figure S1), a univariate analysis method, was used to obtain a 279 first rough ranking of potentially significant features for the 280 differentiation between the two species under study. It is a 281 scatter plot for the two-group data, combining fold change 282 (FC) and $t$ tests. On the $y$-axis is plotted the negative log of 283 the $p$-values so that data points with low $p$-values (highly 284 significant) appear toward the top of the plot. The $x$-axis is the 285 $\log$ of the FC between the two groups B. brizantha/ 286 $B$. decumbens. In this way those points that are found toward 287 the top of the plot that are also far to either the left- or right- 288 hand side represent features displaying large magnitude fold 289 
290 changes as well as high statistical significance. Among features 291 above the set threshold (Table S1) stand out three C-glycosyl 292 flavones (8, 10, and 13), an O-glycosyl flavone (16), two 293 steroidal saponins (19 and 21), and two unidentified compounds 294 (7 and 11), specific for B. decumbens, as well as an O-glycosyl 295 flavonol (15), two O-glycosyl flavonolignans (17 and 18), and 296 a $C$-glycosyl flavone (3) correlated to B. brizantha, as the most 297 meaningful (Figure S1).

298 The unsupervised method PCA was applied to discover 299 inherent group patterns in the data and to examine whether the 300 metabolites selected by volcano plot are also detected as being 301 significant. This method is called "unsupervised" because it is 302 performed without data labeling with class membership. PCA is 303 a powerful method to perform the dimension reduction of 304 a data set containing hundreds of metabolites, finding only 305 few combinations of them that best explain the total variation 306 in the original data set. In the Figure 2A the PCA scores 307 plot is presented showing the distribution of B. brizantha and 308 B. decumbens samples along PC1 and PC2. The first two 309 principal components (PCs) accounted for $47.4 \%$ and $11.5 \%$ of 310 the variation in the spectral data, respectively. The PCA scores 311 plot shows a visible separation along PC1 of two distinct clusters 312 of samples that are species-specific. In addition, an intraspecies 313 variation within $B$. brizantha samples along PC2 was also 314 observed, which was further investigated. The corresponding 315 loadings plot (Figure 2B) displays the features that are 316 responsible for the separating groups. Those data points that 317 are further from the origin toward the left-hand side than most 318 other points in the plot predominate in B. brizantha, while those 319 toward the right-hand side are highly correlated to $B$. decumbens. 320 In this way, it can be observed that the steroidal saponin 19, 321 the two $C$-glycosyl flavones 12 and 14, and compound 7 322 predominate in $B$. decumbens, while the two $C$-glycosyl flavones 3236 and 4, the O-glycosyl flavonol 15, and the phenolic acid 3241 mostly occur in B. brizantha. All these compounds, except 14 325 and 4, were also selected by volcano plot within the top 50 326 features (see Table S1). Although the steroidal saponin 20 327 seems not to be a strong contributor for the interspecies 328 separation, it appears highly significant for the variation among 329 B. brizantha samples. In addition, the highlighted metabolites 330 by volcano plot $\mathbf{8}, \mathbf{1 0}, \mathbf{1 7}, \mathbf{1 8}$, and 21 (Figure S1) were also 331 detected in PCA loadings plot (Figure 2B); however, they 332 contribute less to discrimination between the two groups.

333 The observed intraspecies variation for B. brizantha along 334 PC2 was further investigated by creating a separate PCA model 335 and dendrogram. In the Figure S4 the PCA scores plot, loadings 336 plot, and the corresponding dendrogram are presented. The 337 scores plot displayed separation in PC1 of spring samples along 338 with those harvested in winter at the shorter cutting height, from 339 samples collected in autumn, summer, and those from winter at 340 the higher cutting height. Consistent with that observed in 341 Figure 2B, the loadings plot also showed the steroidal saponin 20 342 as the most significant variable for such separation (Figure S4). 343 These results are in agreement with the hierarchical cluster 344 analysis (HCA) where samples were grouped into two major 345 classes with the largest Euclidean distance value using ward 346 clustering algorithm (Figure S4). One of these classes consists of 347 spring samples together with winter samples collected at the 348 shorter cutting height, while the other is composed by the rest 349 of samples. In the same way, $B$. decumbens was also investigated 350 for intraspecies variations. Its PCA scores plot and dendrogram 351 (Figure S5) displayed a comparable clustering pattern to 352 B. brizantha, with samples collected in spring and winter clearly
19
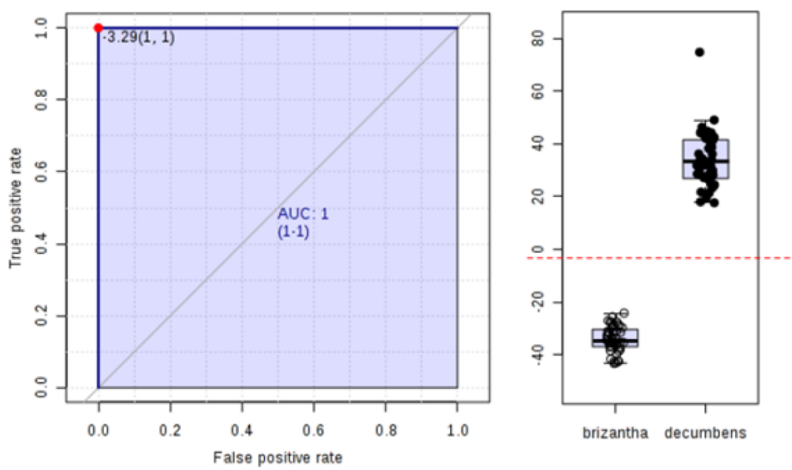

4
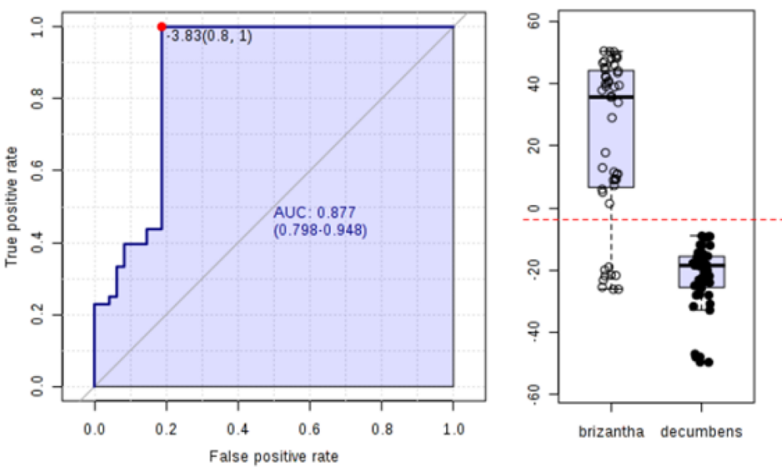

Figure 4. Receiver operating characteristic (ROC) curve for the top two discriminating metabolites. For each of them, the left panel shows the area under the ROC curve (AUC), true-positive and false-positive rates, and confidence interval; the right panel shows the relative concentration of metabolite in B. brizantha and B. decumbens.

separated from those harvested in summer and autumn. Again, 353 the steroidal saponins $\mathbf{1 9}$ and $\mathbf{2 0}$ are the variables responsible for 354 such variation, as can be found in the loadings plot (Figure S5). 355

To further investigate the clustering pattern in the whole data 356 set and the ability of significant metabolites detected by PCA 357 to discriminate between $B$. brizantha and $B$. decumbens, a 358 supervised PLS-DA approach was applied. It uses multivariate 359 regression techniques to extract via linear combination of 360 original variables $(X)$ the information that can predict the 361 group membership $(Y)$. The three-dimensional PLS-DA scores 362 plot between PC1 (47.4\%), PC2 (10.5\%), and PC3 (4.1\%) 363 shows a perfect separation between both species along PC1 364 (Figure 3A). Consistent with PCA, the top contributor to this 365 separation highly correlated to $B$. decumbens is the steroidal 366 saponin 19, although the $C$-glycosyl flavones 12 and 14 and 367 compound 7 are also significant, as shown the PLS-DA loadings 368 plot (Figure 3B), whereas those associated with B. brizantha 369 includes the $C$-glycosyl flavone $\mathbf{4}$ as the most significant, along 370 with other $C$-glycosyl flavone (6), a steroidal saponin (20), an 371 $O$-glycosyl flavonol (15), and a phenolic acid (1). These 372 metabolites were also the most meaningful contributors to PLS- 373 DA component 1 based on variables important in projection (VIP) 374 (Figure 3C). VIP is a weighted sum of squares of the PLS loadings 375 taking into account the amount of explained $Y$-variation in each 376 dimension. The steroidal saponin 19 and the $C$-glycosyl flavone 4377 had the top VIP scores, which in turn means that they can 378 satisfactorily explain most of the variation between both species. 379

In order to assess the statistical significance of the group 380 discrimination obtained by PLS-DA model, a permutation test 381 

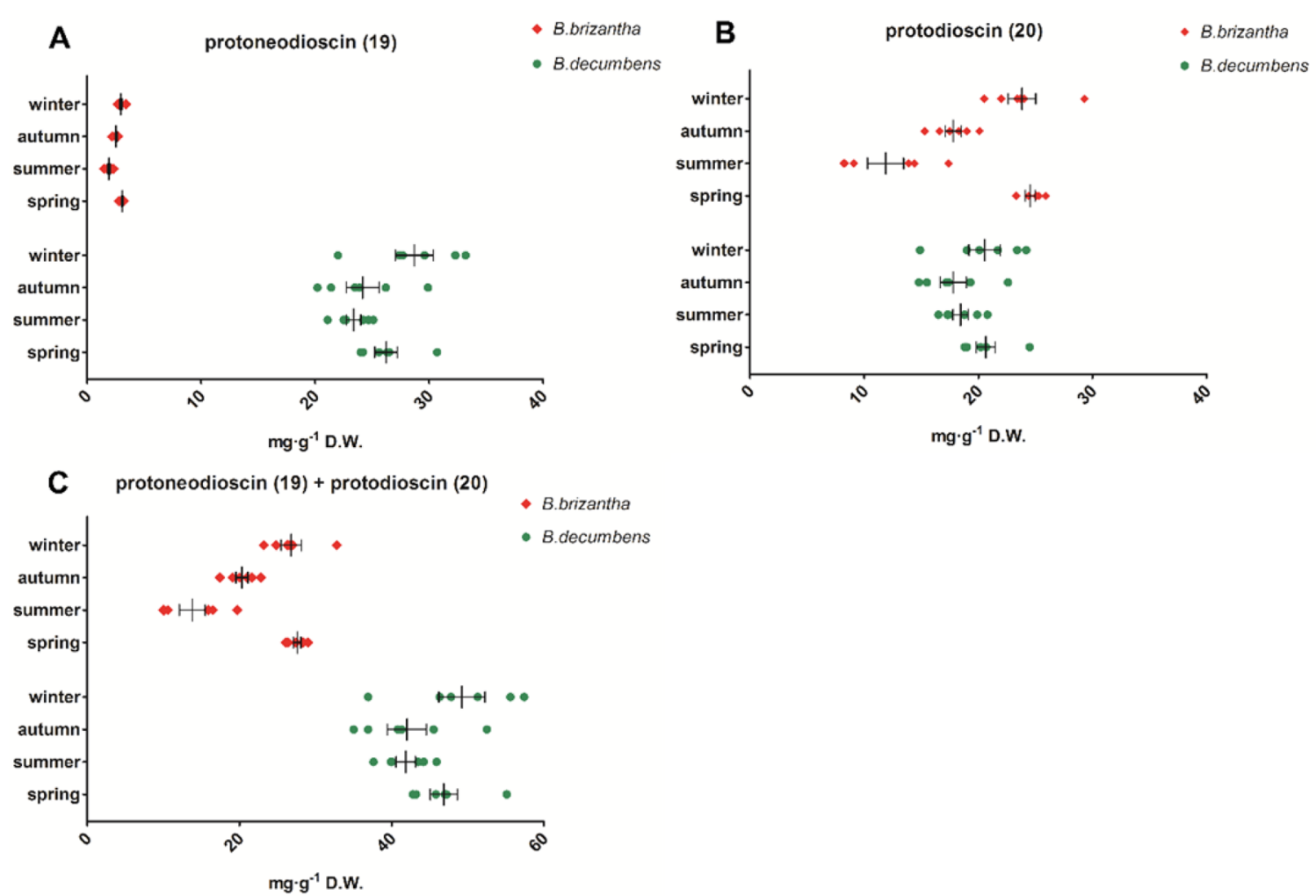

Figure 5. Aligned dot graphs showing the concentrations of protoneodioscin (19), protodioscin (20), and their sum among B. decumbens and $B$. brizantha samples; mean with SEM is shown per each season. Two-way ANOVA analyses for the species and seasonal effects indicated that (A) species, extremely significant $(p<0.0001)$, and seasons, very significant $(p=0.0043)$; (B) species, not significant $(p=0.8433)$, and seasons, extremely significant $(p<0.0001)$; (C) species, extremely significant $(p<0.0001)$, and seasons, extremely significant $(p<0.0001)$.

382 was performed. In each permutation, a PLS-DA model was 383 built between the data $(X)$ and the permuted group labels $384(Y)$ using the optimal number of components determined by 385 cross-validation for the model based on the original group 386 assignment. The separation distance is based on the ratio of 387 the between sum of the squares and the within sum of squares 388 ( $B / W$ ratio $)$ for the group assignment prediction of each model 389 (Figure 3D). The observed test statistic was not part of the 390 distribution based on the permutation group assignments and 391 the $p$-value was $<0.05$, thus demonstrating that the PLS-DA 392 model was reliable.

393 The area under the receiver operating characteristic (ROC) 394 curve (AUC) was also used to evaluate the false-positive rate 395 (1-specificity) and true-positive rate (sensitivity) of individual 396 metabolites for distinguishing B. decumbens and B. brizantha. 397 The AUC value is a measure of the ability of a given metabolite 398 to correctly classify the population as belonging to $B$. decumbens 399 or B. brizantha. The closer the AUC value is to 1.0, the better is 400 the examined metabolite in discriminating the two populations. 401 Figure 4 shows the ROC curves for the top two discriminating 402 metabolites, with AUC $=1.0$ for the saponin 19 and $\mathrm{AUC}=$ 4030.877 for the $C$-glycosyl flavone 4 .

404 These findings suggest that the steroidal saponin 19 (proto405 neodioscin) is the major source of variation or a biomarker for 406 B. decumbens when compared to B. brizantha, which in turn is 407 described here for the first time in these species. Paradoxically, 408 its stereoisomer 20 (protodioscin), which has been linked 409 with the outbreaks causes, ${ }^{7-10}$ seems to be closely related to 410 B. brizantha. This indicates that toxicity in Brachiaria, at least, 411 should not be directly attributed to this compound as pre412 viously thought, but perhaps to protoneodioscin (19) instead.

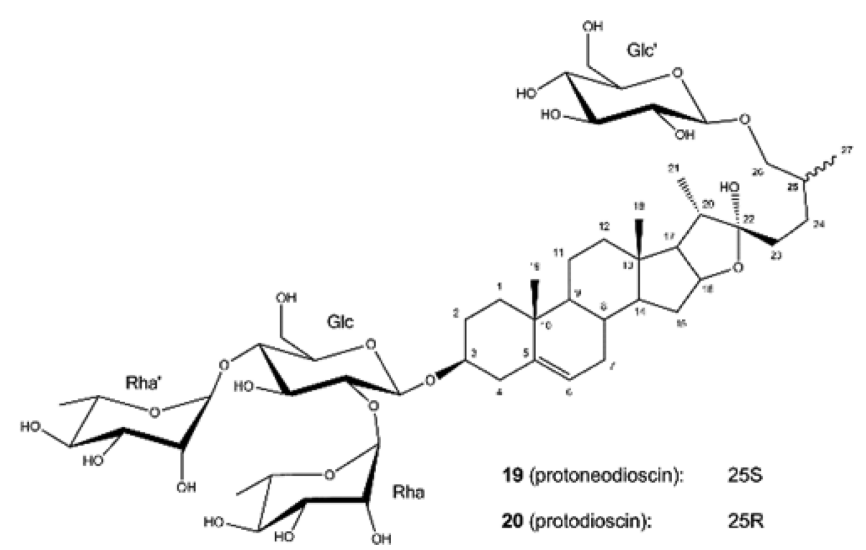

Figure 6. Structures of saponins 19 and 20 isolated from Brachiaria.

To confirm this, we carried out quantification of these two 413 steroidal saponins among samples from both species and 414 performed corresponding statistical analyses.

Quantification of Protoneodioscin and Protodioscin. 416 The quantification of saponins $\mathbf{1 9}$ and $\mathbf{2 0}$ were carried out 417 using a five point calibration curve, which showed excellent 418 fitting to a second-order polynomial (quadratic) equation 419 (Figure S6). Analyses were performed in a UPLC-TQ-MS in 420 positive ion mode, using selected ion monitoring (SIM) of the 421 cationized molecule at $\mathrm{m} / z 1071.5[\mathrm{M}+\mathrm{Na}]^{+}$and retention 422 times of 17.70 and $18.74 \mathrm{~min}$ for 19 and 20, respectively. All 423 obtained values (mean \pm SD) are quoted in milligrams of com- 424 pound per gram of dried weight of plant material (mg.g ${ }^{-1}$ D.W. ${ }_{425}$ and are presented in Supporting Information Table S2. 426 
Table 1. Tentative Identification of Most Significant Metabolites for Distinguishing Groups and Occurrence in B. decumbens (Bd) and B. brizantha (Bb)

\begin{tabular}{|c|c|c|c|c|c|c|c|c|}
\hline no. & $\begin{array}{l}\mathrm{RT} \\
(\mathrm{min})\end{array}$ & measd mass (neg) & $\begin{array}{l}\text { error } \\
(\mathrm{ppm})\end{array}$ & formula & $\mathrm{MS}^{2}$ diagnostic ions, $m / z$ (intensity $\%$ ) & identification & $\mathrm{Bd}$ & $\mathrm{Bb}$ \\
\hline \multicolumn{9}{|c|}{ Phenolic Acids } \\
\hline 1 & 5.74 & $353.0868[\mathrm{M}-\mathrm{H}]^{-}$ & 2.9 & $\mathrm{C}_{16} \mathrm{H}_{18} \mathrm{O}_{9}$ & $191(100), 179(41), 161(7)$ & 3-CQA & + & + \\
\hline 2 & 9.31 & $353.0874[\mathrm{M}-\mathrm{H}]^{-}$ & 1.3 & $\mathrm{C}_{16} \mathrm{H}_{18} \mathrm{O}_{9}$ & 191 (100), 179 (58), $173(57), 161$ (12) & 4-CQA & + & + \\
\hline \multicolumn{9}{|c|}{$C$ - and $C, O-G l y c o s y l$ Flavones } \\
\hline 3 & 11.81 & $609.1447[\mathrm{M}-\mathrm{H}]^{-}$ & 2.2 & $\mathrm{C}_{27} \mathrm{H}_{30} \mathrm{O}_{16}$ & $\begin{array}{l}447(8), 357(28), 327(100), 313(46) \\
298(21)\end{array}$ & orientin $2^{\prime \prime}$-O-glucoside & - & + \\
\hline 4 & 13.05 & $579.1357[\mathrm{M}-\mathrm{H}]^{-}$ & -0.2 & $\mathrm{C}_{26} \mathrm{H}_{28} \mathrm{O}_{15}$ & $\begin{array}{l}489(5), 459(12), 429(29), 399(95) \\
369 \text { (100) }\end{array}$ & carlinoside & + & + \\
\hline 5 & 14.25 & $563.1404[\mathrm{M}-\mathrm{H}]^{-}$ & 0.4 & $\mathrm{C}_{26} \mathrm{H}_{28} \mathrm{O}_{14}$ & $\begin{array}{l}473(16), 443(24), 413(13), 383(71) \\
\quad 353 \text { (100) }\end{array}$ & schaftoside & + & + \\
\hline 6 & 14.35 & $593.1513[\mathrm{M}-\mathrm{H}]^{-}$ & -0.1 & $\mathrm{C}_{27} \mathrm{H}_{30} \mathrm{O}_{15}$ & $\begin{array}{l}473(18), 447(0.8), 357(20), 327(36) \\
298(100)\end{array}$ & orientin 7-O-rhamnoside & - & + \\
\hline 8 & 15.80 & $533.1302[\mathrm{M}-\mathrm{H}]^{-}$ & -0.3 & $\mathrm{C}_{25} \mathrm{H}_{26} \mathrm{O}_{13}$ & $\begin{array}{l}515(15), 473(29), 443(34), 413(18) \\
\quad 383(100), 353(95)\end{array}$ & apigenin 6,8-di- $C$-arabinoside & + & - \\
\hline 9 & 16.38 & $579.1351[\mathrm{M}-\mathrm{H}]^{-}$ & 0.7 & $\mathrm{C}_{26} \mathrm{H}_{28} \mathrm{O}_{15}$ & $\begin{array}{l}489(25), 417(6), 357(22), 327(46) \\
298(100)\end{array}$ & $\begin{array}{l}2^{\prime}, 4^{\prime}, 5,7 \text {-tetrahydroxy-flavone- } 8-C \text { - } \\
\text { arabinosyl-7-O-glucoside }\end{array}$ & - & + \\
\hline 10 & 17.34 & $607.1673[\mathrm{M}-\mathrm{H}]^{-}$ & -0.8 & $\mathrm{C}_{28} \mathrm{H}_{32} \mathrm{O}_{15}$ & $\begin{array}{l}533(4), 503(6), 475(14), 445(10) \\
429(44), 401(8), 371(13), 341(54) \\
327(100), 312(30)\end{array}$ & $\begin{array}{l}\text { diosmetin-8-C-rhamnosyl-7-O- } \\
\text { glucoside }\end{array}$ & + & - \\
\hline $12^{a}$ & 17.56 & $563.1411[\mathrm{M}-\mathrm{H}]^{-}$ & -0.8 & $\mathrm{C}_{26} \mathrm{H}_{28} \mathrm{O}_{14}$ & $\begin{array}{l}503(5), 473(15), 429(26), 399(100) \\
369 \text { (78) }\end{array}$ & $\begin{array}{l}\text { luteolin 6-C-pentosyl-8-C- } \\
\text { deoxyhexoside }\end{array}$ & + & - \\
\hline $13^{a}$ & 18.61 & $547.1456[\mathrm{M}-\mathrm{H}]^{-}$ & 0.2 & $\mathrm{C}_{26} \mathrm{H}_{28} \mathrm{O}_{13}$ & $\begin{array}{l}503(4), 473(25), 443(19), 413(17) \\
\quad 383(100), 353(89)\end{array}$ & $\begin{array}{l}\text { apigenin } 6-C \text {-deoxyhexosyl-8- } C \text { - } \\
\text { pentoside }\end{array}$ & + & - \\
\hline 14 & 19.52 & $575.1408[\mathrm{M}-\mathrm{H}]^{-}$ & -0.3 & $\mathrm{C}_{27} \mathrm{H}_{28} \mathrm{O}_{14}$ & $\begin{array}{l}429(4), 411(10), 385(9), 367(23) \\
325(100), 298(62), 285(24)\end{array}$ & cassiaoccidentalin B & + & + \\
\hline 7 & 15.70 & $401.1821[\mathrm{M}-\mathrm{H}]^{-}$ & -0.9 & $\mathrm{C}_{19} \mathrm{H}_{30} \mathrm{O}_{9}$ & 401 (100), $221(39), 195$ (32), 177 (38) & unidentified & + & - \\
\hline 11 & 17.52 & $533.1314[\mathrm{M}-\mathrm{H}]^{-}$ & -2.5 & $\mathrm{C}_{25} \mathrm{H}_{26} \mathrm{O}_{13}$ & & unidentified & + & - \\
\hline \multicolumn{9}{|c|}{ O-Glycosyl Flavonol } \\
\hline 15 & 19.33 & $637.1770[\mathrm{M}-\mathrm{H}]^{-}$ & 0.7 & $\mathrm{C}_{29} \mathrm{H}_{33} \mathrm{O}_{16}$ & $\begin{array}{l}607(7), 491(6), 461(5), 329(100) \\
313(84), 299(57), 271(16)\end{array}$ & ombuin-3-O-rutinoside & - & + \\
\hline & & & & & O-Glycosyl Flavone & & & \\
\hline 16 & 20.30 & $491.1202[\mathrm{M}-\mathrm{H}]^{-}$ & -1.5 & $\mathrm{C}_{23} \mathrm{H}_{24} \mathrm{O}_{12}$ & $\begin{array}{l}459(6), 323(13), 315(38), 175(83) \\
\quad 152(100)\end{array}$ & tricin 7 -O-glucoside & + & - \\
\hline \multicolumn{9}{|c|}{ Flavonolignans } \\
\hline $17^{a}$ & 20.42 & $833.2511[\mathrm{M}-\mathrm{H}]^{-}$ & -0.2 & $\mathrm{C}_{39} \mathrm{H}_{46} \mathrm{O}_{20}$ & 637 (100), $525(6), 477(11), 329(80)$ & $\begin{array}{l}\text { tricin } 44^{\prime}-O-(\beta \text {-guaiacylglyceryl }) \\
\text { ether } 7-O-(\text { deoxyhexosyl })- \\
\text { glucoside (isomer } 1)\end{array}$ & - & + \\
\hline $18^{a}$ & 20.95 & $833.2516[\mathrm{M}-\mathrm{H}]^{-}$ & -0.8 & $\mathrm{C}_{39} \mathrm{H}_{46} \mathrm{O}_{20}$ & 637 (100), 477 (4), $329(81)$ & $\begin{array}{l}\text { tricin } 4^{\prime}-O-(\beta \text {-guaiacylglyceryl }) \\
\text { ether } 7-O \text {-(deoxyhexosyl)- } \\
\text { glucoside (isomer } 2)\end{array}$ & - & + \\
\hline \multicolumn{9}{|c|}{ Steroidal Saponins } \\
\hline 19 & 23.61 & $\begin{array}{l}1093.5421 \\
{[\mathrm{M}+\mathrm{HCOOH}-\mathrm{H}]^{-}}\end{array}$ & 1.4 & $\mathrm{C}_{51} \mathrm{H}_{84} \mathrm{O}_{22}$ & $\begin{array}{l}901(10), 755(39), 593(26), 575(38) \\
\quad 431(100)\end{array}$ & protoneodioscin & + & + \\
\hline 20 & 23.80 & $\begin{array}{l}1093.5417 \\
{[\mathrm{M}+\mathrm{HCOOH}-\mathrm{H}]^{-}}\end{array}$ & 1.8 & $\mathrm{C}_{51} \mathrm{H}_{84} \mathrm{O}_{22}$ & $\begin{array}{l}901(8), 755(28), 593(20), 575(15) \\
431(100)\end{array}$ & protodioscin & + & + \\
\hline 21 & 30.50 & $\begin{array}{l}1135.5505 \\
{[\mathrm{M}+\mathrm{HCOOH}-\mathrm{H}]^{-}}\end{array}$ & 3.2 & $\mathrm{C}_{53} \mathrm{H}_{86} \mathrm{O}_{23}$ & $\begin{array}{l}901(15), 755(27), 593(35), 575(17) \\
\quad 431(100)\end{array}$ & acetyl-protodioscin & + & - \\
\hline
\end{tabular}

427 For comparison, each obtained value for the content of these 428 saponins in $B$. decumbens and B. brizantha was presented in dot 429 graphs, where data points dispersion is well-visible (Figure 5). 430 The concentration of protoneodioscin (19) in B. decumbens 431 (Figure 5A) was higher than $20 \mathrm{mg} \cdot \mathrm{g}^{-1} \mathrm{D} . \mathrm{W}$. in all seasons, 432 reaching even greater levels in some cases, like in winter $433\left(31.07 \pm 2.9 \mathrm{mg} \cdot \mathrm{g}^{-1} \mathrm{D} . \mathrm{W}\right.$. $)$. These values were, however, found 434 to be not significantly different among seasons $(p>0.05)$ 435 (Figure S7). By contrast, the content of this compound was 436 considerably different in B. brizantha $(p<0.05)$, with values 4375 times lower than in $B$. decumbens, and never reaching more 438 than $4 \mathrm{mg} \cdot \mathrm{g}^{-1}$ D.W. Although important variations of the 439 protodioscin (20) content within seasons were found in 440 B. brizantha, especially in the summer when the lowest amount 441 was registered $\left(8.53 \pm 0.5 \mathrm{mg} \cdot \mathrm{g}^{-1} \mathrm{D} . \mathrm{W}.\right)$, the values were not significantly different from those of B. decumbens (Figure 5B). 442 This puts into question that only protodioscin (20) can exert 443 the toxicity in Brachiaria, particularly when much higher 444 concentrations of this compound were found in the less toxic 445 species (B. brizantha) in spring $\left(24.83 \pm 1.4 \mathrm{mg} \cdot \mathrm{g}^{-1}\right.$ D.W. $) 446$ and winter $\left(25.47 \pm 3.3 \mathrm{mg} \cdot \mathrm{g}^{-1}\right.$ D.W. $)$. Hence, the added 447 value of protoneodioscin for the total saponin concentration 448 in $B$. decumbens could be crucial. Obviously, the sum of these 449 two saponins in $B$. decumbens was considerably higher than 450 in B. brizantha (Figure 5C), ranging from $4.1 \%$ to $5.3 \%$ of the 451 dry weight (Table S2), while in B. brizantha they were only 452 between $1.0 \%$ and $2.9 \%$.

The variation in concentration of saponins 19, 20, and their 454 sum between different cutting heights within seasons were also 455 investigated by one-way ANOVA (Table S2). In B. decumbens 456 
457 the saponins concentrations were not significantly different 458 either within seasons or plant heights (Figure S7). B. brizantha, 459 however, showed different properties (Figure S8), especially for 460 the content of $\mathbf{2 0}$ that significantly changes within summer, 461 being lower also when plants are younger ( $15 \mathrm{~cm}$ height).

462 Despite that metabolomics study can hardly give hints 463 regarding bioactivity of a specific secondary metabolite, there 464 are previous investigations that may validate our findings. 465 Lajis et al. reported the isolation of epi-sarsasapogenin and $466 \mathrm{epi}$-smilagenin from the rumen content of sheep intoxicated 467 by $B$. decumbens. ${ }^{21}$ The crystals deposited in the biliary system 468 of intoxicated livestock, which are products of a detoxification, 469 were reported as insoluble salts of epi-sarsasapogenin and 470 epi-smilagenin glucuronates. ${ }^{22}$ It is important to note that these 471 two spirostanol sapogenins differ only in their configuration around 472 carbon 25, just as the difference between protoneodioscin (19) 473 and protodioscin (20). epi-Sarsasapogenin and epi-smilagenin 474 are considered to be the metabolized products of saponins 19 475 and 20, respectively.

476 Metabolites Identity Assignment. To achieve unambig477 uous identification of compounds 19 and 20, they were isolated 478 and then elucidated based on a combination of NMR, HRMS, 479 and MS/MS techniques (Figures S9-S20). Compound 19 had 480 NMR spectroscopic characteristics identical to those of proto481 neodioscin, a furostanol-type steroidal saponin (Figure 6). ${ }^{19}$ 482 To our knowledge, this is the first time protoneodioscin was 483 detected in Brachiaria genus. Compound 20 showed NMR data 484 almost superimposable to that of 19 , except for small differences 485 in the chemical shifts of the opened ring F (Supporting 486 Information Table S3). It was finally identified as protodioscin, 487 also a furostanol-type steroidal saponin. ${ }^{19,20}$ The structures of 488 these two saponins basically differ only in the configuration 489 around carbon 25 . This was deduced as $25 S$ for 19 and $25 R$ for 490 20, according to the Agrawal's rule, which is based on the 491 difference in the chemical shifts between germinal protons of 492 the glycosyloxy methylene $\mathrm{H}_{2}-26\left(\Delta_{\mathrm{ab}}=\delta_{\mathrm{a}}-\delta_{\mathrm{b}}\right)$, establishing 493 the configuration as $25 R$ if $\Delta_{\mathrm{ab}}<0.48$ or $25 S$ if $\Delta_{\mathrm{ab}}>0.57 .^{23}$ 494 The fragmentation patterns observed in MS/MS spectra of 19 495 and 20 (Figures S19 and S20) were identical, displaying neutral 496 losses of two deoxyhexoses and two hexoses (Table 1).

497 Remaining compounds (Table 1) were tentatively identified 498 based on tandem mass spectrometry (MS/MS), metabolite 499 database of METLIN, ${ }^{17}$ authentic standards, and data available 500 in the literature. In this way, the two phenolic acid isomers $501 \mathbf{1}$ and $\mathbf{2}$ were assigned as 3-O-caffeoylquinic acid (3-CQA) 502 and 4-O-caffeoylquinic acid (4-CQA), respectively. ${ }^{24}$ The $50310 \mathrm{C}$-glycosyl flavones were identified as orientin $2^{\prime \prime}$-O504 glucoside (3), ${ }^{25}$ carlinoside (4), ${ }^{26}$ schaftoside (5), ${ }^{25}$ orientin 505 7-O-rhamnoside $(6){ }^{27}$ apigenin 6,8 -di-C-arabinoside $(8){ }^{28}$ $5062^{\prime}, 4^{\prime}, 5,7$-tetrahydroxy-flavone-8- $C$-arabinosyl-7- $O$-glucoside 507 (9), ${ }^{29}$ diosmetin-8-C-rhamnosyl-7-O-glucoside (10), ${ }^{30}$ luteolin 508 6-C-pentosyl-8-C-deoxyhexoside (12), apigenin 6- $C$-deoxy509 hexosyl-8-C-pentoside (13), and cassiaoccidentalin B (14). ${ }^{26}$ 510 To our knowledge, compounds 12 and 13 have not been 511 reported before from Brachiaria or other natural source; 512 therefore, they represent presumably new natural compounds. 513 The $O$-glycosyl flavonoids $\mathbf{1 5}$ and $\mathbf{1 6}$ were identified as being 514 ombuin-3-O-rutinoside ${ }^{31}$ and tricin $7-O$-glucoside, ${ }^{32}$ respec515 tively. On the basis of the similarities of MS/MS fragmentation 516 patterns with related phytochemicals, the two glycosyl 517 flavonolignan isomers $\mathbf{1 7}$ and $\mathbf{1 8}$ were assigned as tricin $4^{\prime}$-O$518(\beta$-guaiacylglyceryl $)$ ether 7-O-(O-deoxyhexosyl)-glucoside, ${ }^{32}$ 519 which presumably are also new natural compounds. Compound
21 was identified as acetyl protodioscin, ${ }^{33}$ whereas compounds 520 7 and 11 remain unidentified.

\section{ASSOCIATED CONTENT}

522

\section{Supporting Information}

523

The Supporting Information is available free of charge on the 524 ACS Publications website at DOI: 10.1021/acs.jafc.6b01296. 525

Tables with quantitative and NMR data for proto- 526 neodioscin (19) and protodioscin (20), volcano plot, 527 PCA scree plot and biplot, PCA and HCA for 528 intraspecies variation, copies of NMR spectra including 529 ${ }^{1} \mathrm{H},{ }^{13} \mathrm{C}, \mathrm{HMBC}$, COSY DQF, HSQC, TROESY, and 530 HR-QTOF-MS/MS for compounds 19 and 20 (PDF) 531

\section{AUTHOR INFORMATION}

\section{Corresponding Author}

*E-mail: aperez@iung.pulawy.pl. Phone: +48 814786886.

This work was funded by the Statutory Activities of the 536 Institute of Soil Science and Plant Cultivation-State Research 537 Institute and by Twas-CNPq Postgraduate Fellowship Pro- 538 gramme (Process No. 190178/2012-4).

Notes

The authors declare no competing financial interest.

\section{REFERENCES}

542

(1) FAOSTAT database. Food and Agriculture Organization of the 543 United Nation. http://faostat3.fao.org/browse/Q/QA/E (accessed 544 December 22, 2014).

(2) Vigna, B. B. Z.; Jungmann, L.; Francisco, P. M.; Zucchi, M. I.; do 546 Valle, C. B.; de Souza, A. P. Genetic diversity and population structure 547 of the Brachiaria brizantha germplasm. Trop. Plant Biol. 2011, 4, 157- 548 169.

549

(3) Riet-Correa, B.; Castro, M. B.; Lemos, R. a.; Riet-Correa, G.; 550 Mustafa, V.; Riet-Correa, F. Brachiaria spp. poisoning of ruminants in 551 Brazil. Pesqui. Veterinária Bras. 2011, 31, 183-192.

(4) Furlan, F. H.; Colodel, E. M.; Lemos, R. A. A.; Castro, M. B.; 553 Mendoça, F. S.; Riet-Correa, F. Poisonous plant affecting cattle in 554 Central-Western Brazil. Int. J. Poisonous Plant Res. 2012, 2, 1-13. 555

(5) Tokaria, C. H.; Brito, M. F.; Barbosa, J. D.; Peixoto, P. V.; 556 Döbereiner, J. Plantas Toxicas do Brasil: Para as Animais de Produção, 557 2nd ed.; Editora Helianthus: Rio de Janeiro, Brazil, 2012.

558

(6) Driemeier, D.; Colodel, E. M.; Seitz, A. L.; Barros, S. S.; Cruz, C. 559 E. F. Study of experimentally induced lesions in sheep by grazing 560 Brachiaria decumbens. Toxicon 2002, 40, 1027-1031.

561

(7) Cruz, C. E. F.; Driemeier, D.; Pires, V. S.; Schenkel, E. P. 562 Experimentally induced cholangiohepatopathy by dosing sheep with 563 fractionated extracts from Brachiaria decumbens. J. Vet. Diagn. Invest. 564 2001, 13, 170-172.

(8) Saturnino, K. C.; Mariani, T. M.; Barbosa-Ferreira, M.; Brum, K. 566 B.; dos Santos Fernandes, C. E.; Lemos, R. A. A. Intoxicação 567 experimental por Brachiaria decumbens em ovinos confinados. Pesq. 568 Vet. Bras. 2010, 30, 195-202.

569

(9) Driemeier, D.; Döbereiner, J.; Peixoto, P. V.; Brito, M. F. Relação 570 entre macrófagos espumosos ("foam cells") no fígado de bovinos e 571 ingestão de Brachiaria spp no Brasil. Pesq. Vet. Bras. 1999, 19, 79-83. 572

(10) Lemos, R. A. A.; Salvador, S.; Nakazato, L. Photosensitization 573 and crystal-association cholangiohepatopathy in cattle grazing 574 Brachiaria decumbens in Brazil. Vet. Hum. Toxicol. 1997, 39, 376-377. 575

(11) Quinn, J. C.; Kessell, A.; Weston, L. a. Secondary plant products 576 causing photosensitization in grazing herbivores: Their structure, 577 activity and regulation. Int. J. Mol. Sci. 2014, 15, 1441-1465. 578

(12) Gracindo, C. V.; Louvandini, H.; Riet-Correa, F.; Barbosa- 579 Ferreira, M.; de Castro, M. B. Performance of sheep grazing in 580 pastures of Brachiaria decumbens, Brachiaria brizantha, Panicum 581 
582 maximum, and Andropogon gayanus with different protodioscin 583 concentrations. Trop. Anim. Health Prod. 2014, 46, 733-737. 584 (13) Rathahao-Paris, E.; Alves, S.; Junot, C.; Tabet, J.-C. High 585 resolution mass spectrometry for structural identification of metabo586 lites in metabolomics. Metabolomics 2016, 12, 1-15.

587 (14) Allwood, J. W.; de Vos, R. C.; Moing, A.; Deborde, C.; Erban, 588 A.; Kopka, J.; Goodacre, R.; Hall, $\mathrm{D} \cap \mathrm{D}$ Dlant matabonomicc and jts 589 potential for systems biology Note Added after 590 technology, and methodology. Met ASAP Publication 591 (15) Xiong, A.; Yang, L.; Ji, L.; W 592 X.; Wang, C.; Wang, Z. UPLC-N This article 593 Senecio scandens and S. vulgaris: an published May 18, 594 two Senecio herbs with similar n2016 with an author y. 595 Metabolomics 2012, 8, 614-623. 596 (16) Viljoen, A. M.; Zhao, J.; S. 597 Phytochemical distinction between ind 598 bo") and $P$. reniforme throug 599 metabolomic profiling. Metabolomi 600 (17) Smith, C. A.; O’Maille, G.; $\gamma$ corrected and reposted .; 601 Brandon, T. R.; Custodio, D. E.; Al on June 8, 2016. 602 metabolite mass spectral database. 603751 .

604 (18) Xia, J.; Sinelnikov, I. V.; Han, B.; Wishart, D. S. MetaboAnalyst 605 3.0-making metabolomics more meaningful. Nucleic Acids Res. 2015, 606 43, W251-W257.

607 (19) Hu, K.; Dong, A.; Yao, X.; Kobayashi, H.; Iwasaki, S. 608 Antineoplastic agents; II. Four furostanol glycosides of Dioscorea 609 collettii var. hypoglauca. Planta Med. 1997, 63, 161-165.

610 (20) Huang, H. L.; Liu, R. H.; Shao, F. Structural determination of 611 two new steroidal saponins from Smilax china. Magn. Reson. Chem. 612 2009, 47, 741-745.

613 (21) Lajis, N. H.; Abdullah, A. S. H.; Salim, S. J. S.; Bremmer, J. B.; 614 Khan, M. N. Epi-sarsasapogenin and epi-smilagenin: two sapogenins 615 isolated from the rumen content of sheep intoxicated by Brachiaria 616 decumbens. Steroids 1993, 58, 387-389.

617 (22) Flåøyen, A. Do steroidal saponins have a role in hepatogenous 618 photosensitization diseases of sheep? In Saponins Used in Food and 619 Agriculture, 1st ed.; Waller, G. R., Yamasaki, K., Eds.; Plenum Press: 620 New York, 1996; p 395.

621 (23) Agrawal, P. K. Assigning stereodiversity of the 27-Me group of 622 furostane-type steroidal saponins via NMR chemical shifts. Steroids $6232005,70,715-724$.

624 (24) Clifford, M.; Johnston, K.; Knight, S.; Kuhnert, N. A hierarchical 625 scheme for LC-MS ${ }^{\mathrm{n}}$ identification of chlorogenic acid. J. Agric. Food 626 Chem. 2003, 51, 2900-2911.

627 (25) Ferreres, F.; Silva, B. M.; Andrade, P. B.; Seabra, R. M.; Ferreira, $628 \mathrm{M}$. A. Approach to the study of $C$-glycosyl flavones by ion trap HPLC629 PAD-ESI/MS/MS: Application to seeds of quince (Cydonia oblonga). 630 Phytochem. Anal. 2003, 14, 352-359.

631 (26) Costa, G.; Ferreira, J. P.; Vitorino, C.; Pina, M. E.; Sousa, J. J.; 632 Figueiredo, I. V.; Batista, M. T. Polyphenols from Cymbopogon citratus 633 leaves as topical anti-inflammatory agents. J. Ethnopharmacol. 2016, $634178,222-228$.

635 (27) Ibrahim, R. K.; Shaw, M. Phenolic constituents of the oil flax 636 (linum usitatissimum). Phytochemistry 1970, 9, 1855-1858.

637 (28) Singh, A.; Kumar, S.; Bajpai, V.; Reddy, T. J.; Rameshkumar, K. 638 B.; Kumar, B. Structural characterization of flavonoid $C$ - and $O$ 639 glycosides in an extract of Adhatoda vasica leaves by liquid 640 chromatography with quadrupole time-of-flight mass spectrometry. 641 Rapid Commun. Mass Spectrom. 2015, 29, 1095-1106.

642 (29) Ibrahim, L. F.; Marzouk, M. M.; Hussein, S. R.; Kawashty, S. A.; 643 Mahmoud, K.; Saleh, N. A. M. Flavonoid constituents and biological 644 screening of Astragalus bombycinus Boiss. Nat. Prod. Res. 2013, 27, 645 386-393.

646 (30) Colombo, R.; Yariwake, J. H.; Ferreira, E.; Ndjoko, K.; 647 Hostettmann, K. LC-Ms/Ms analysis of sugarcane extracts and 648 differentiation of monosaccharides moieties of flavone $C$-glycosides. 649 J. Liq. Chromatogr. Relat. Technol. 2013, 36, 239-248.
(31) Simirgiotis, M. J. Antioxidant capacity and HPLC-DAD-MS 650 profiling of chilean peumo (Cryptocarya alba) fruits and comparison 651 with german peumo (Crataegus monogyna) from Southern Chile. 652 Molecules 2013, 18, 2061-2080.

653

(32) Yang, Z.; Nakabayashi, R.; Okazaki, Y.; Mori, T.; Takamatsu, S.; 654 Kitanaka, S.; Kikuchi, J.; Saito, K. Toward better annotation in plant 655 metabolomics: isolation and structure elucidation of 36 specialized 656 metabolites from Oryza sativa (rice) by using MS/MS and NMR 657 analyses. Metabolomics 2014, 10, 543-555. 658 (38) Ivanova, A.; Mikhova, B.; Klaiber, I.; Dinchev, D.; Kostova, I. 659 Steroidax saponins from Smilax excelsa rhizomes. Nat. Prod. Res. 2009, 660 23, 916-924. 